\title{
A Technological Highlights of 5G Network Technology with their Research Challenges
}

\author{
Kuldeep Kumar Somvanshi, Suryakant Pathak
}

\begin{abstract}
In recent years there are many research works is going on in the 5th Generation (5G) networks. Many technologies are explored this area for mobile systems and other. era. In this area there are many challenges in which researchers will have to work to make network available for the users any time anywhere even in dense areas with unlimited capacity of data rate, more flexible network, with more battery life, information about the hand handled devices. In $5 G$ network more improvements and enhancement may be done with standard documentation and Enhanced End-to-End performance for the users and network also can keep track of all devices with latest technologies like with IoT, Artificial Intelligence.

To inspire research work in future, we reveal open problems and we have highlighted several challenges related to $5 G$ network for heterogeneous data and in various industries. Improving spectral utilization is a core focus to cater the ever-increasing demand in data rate and system capacity required for the development of $5 G$.
\end{abstract}

In this paper, we have discussed research work related to the 5 th Generation network and $5 G$ applications, future perspective End to End performance and research challenges related to $5 G$ network communication. Which is the research prone areas for the researchers.

Index Terms: Generation; 5G networks; network traffic; end-to-end performance, context awareness, $5 G$ challenges, Battery life.

\section{INTRODUCTION}

During last two decades world has witnessed rapid evolution of cellular communication technologies from $2 \mathrm{G}$ GSM system to $4 \mathrm{G}$ Long Term Evolution -Advanced (LTE-A). The main motivation has been the requirements of more bandwidth and low latency. Alongside throughput related performance enhancements, some allied parameters like jitter, inter channel interference and connectivity, scalability and compatibility with legacy networks are also taken under consideration. Bandwidth is the measurement of channel capacity or the maximum rate of information transfer possible over a noisy channel. It is generally not possible to send more data over a noisy channel above the Shannon limit and this is the maximum throughput of the channel. As throughput is the actual data transfer rate, it may

Revised Manuscript Received on July 08, 2019.

Kuldeep Kumar Somvanshi, Research Scholar, Computer Science \& Engineering, Dr. KN Modi University Newai, Rajasthan, India, sw.ee.dhanawat@gmail.com

Dr. Suryakant Pathak, Computer Science \& Engineering, Dr. KN Modi Univeristy Newai, Rajasthan, India be smaller than the available bandwidth. The other important parameter latency is the time delay between the sender sending the message and the receiver decoding the same after receiving. Latency largely depends on the processing speed of each of the nodethrough which the data stream traverses.

In recent years, there have been significant developments in the research on 5th Generation (5G) networks. Several enabling technologies are being explored for the $5 \mathrm{G}$ mobile system era. And all the stakeholders from different bodies like, Govt. and Private sectors must work in agreement to bring $5 \mathrm{G}$ to fruition. In our approach we will aggregate the 5G-related tasks and information from these stockholders.

To inspire future research, we reveal open problems and highlight the need for piloting with $5 \mathrm{G}$ applications, with tangible steps, to understand the configuration of $5 \mathrm{G}$ networks and the use of applications across multiple vertical industries.

Improving spectral utilization is a core focus to cater the ever-increasing demand in data rate and system capacity required for the development of $5 \mathrm{G}$.

From the first generation, $1 \mathrm{G}$, to the fourth generation, $4 \mathrm{G}$, the development and technological advancements in telecommunications network systems have been remarkable. Faster and better connections have opened for new markets, ideas and possibilities, to that extent that there now is a demand that surpasses the supply. Despite all these advancements made in the mobile communications field most of the concept of how the technology works and its infrastructure has remained the same. This however, is about to change with the introduction of the fifth generation $(5 \mathrm{G})$ mobile communication.

With the introduction of $5 \mathrm{G}$ much of the technology introduced will be different from that of previous generations. This change extends to include the entire infrastructure of the mobile communications system. With these major changes, many of the tools available today for telecommunications network evaluation do not really suffice to include the $5 \mathrm{G}$ network standard. For this reason, there is a need to develop a new kind of tool that will be able to include the changes brought by this new network standard.

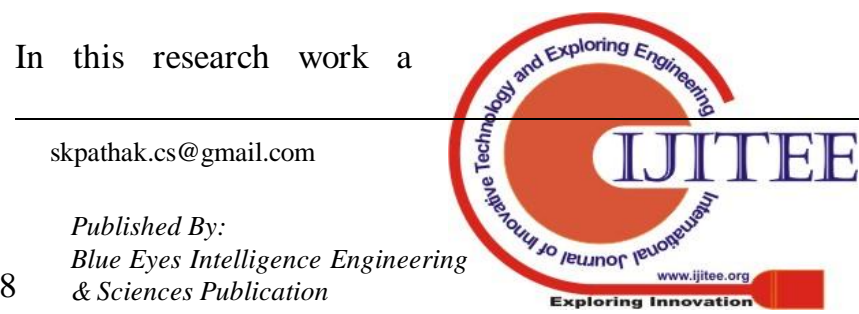


simulation framework adapted for the next generation telecommunication standard $5 \mathrm{G}$ is set to be developed. This framework should include many of the characteristics that set $5 \mathrm{G}$ aside from previous generations.

\subsection{The 5 G network}

$5 \mathrm{G}$ is the first telecommunication standard to use frequencies in the 24-86 GHz range (Medbo and Zaidi, no date). With the use of higher unused frequencies of the radio spectrum will introduce problems were signals have difficulties penetrating obstacles. These obstacles can be buildings trees or even the atmosphere.

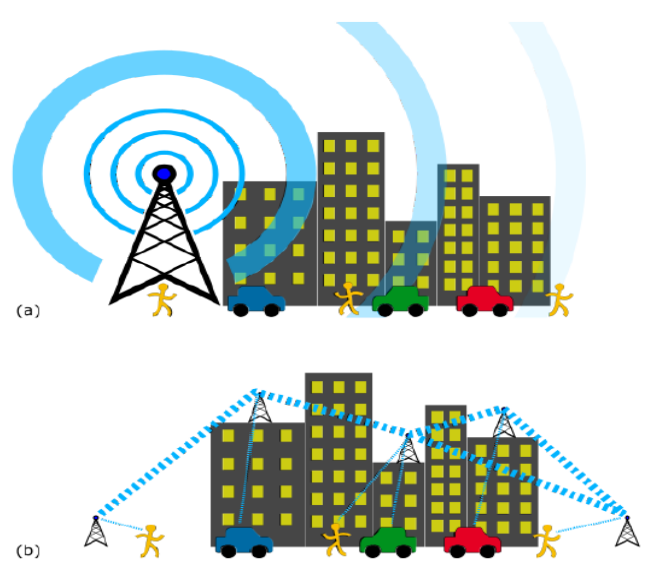

Figure 1: A picture of (a) the current standard of mobile communication infrastructure, with few but powerful cell towers and (b) the future infrastructure with the deployment of the $5 \mathrm{G}$ network.

To solve this a new approach of having several smaller cellular towers is being implemented, together with advanced technologies like beamforming and massive Multiple-Input Multiple-Output (MIMO). These technologies combined are expected to increase efficiency of the cellular towers and enable higher bandwidths, faster connections and lower latencies to the vast number of devices being connected.

In Figure 1, a depiction of the differences between previous technologies and 5G technology can be seen and Figure 2 shows how $5 \mathrm{G}$ network is faster than other technologies.

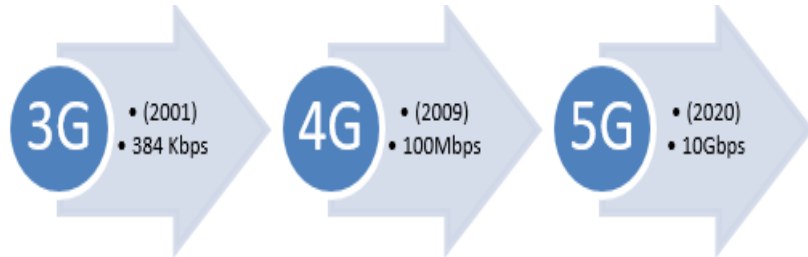

Figure 2 Growth of $5 \mathrm{G}$ Networks over $3 \mathrm{G}$ and $4 \mathrm{G}$ networks

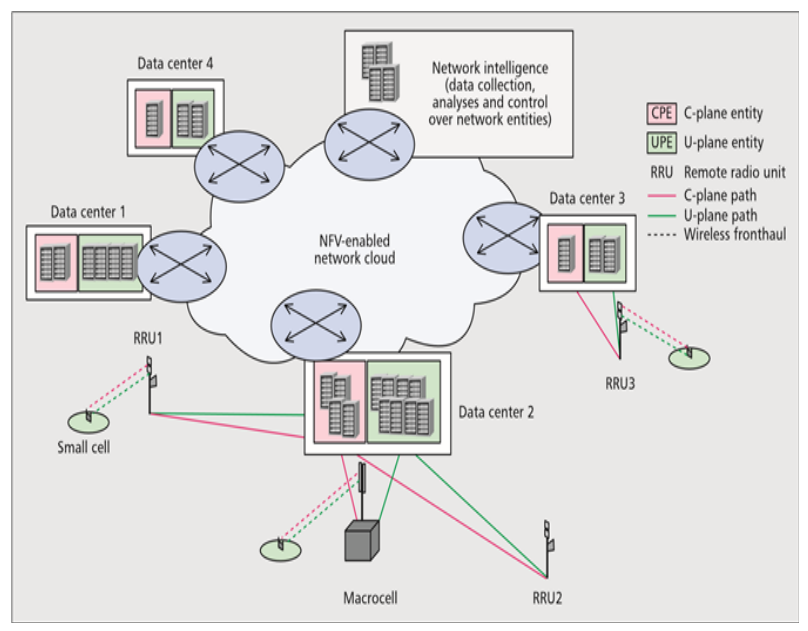

Figure 3 Network Architecture of 5G

The Figure 3 shows the network architecture of 5G, with radio network and a network cloud layers and base stations. The difference between all the 5 generations LTE's are shown Table 1:

Table 1: Comparative analysis of different Generation attributes or network technologies

\begin{tabular}{|l|l|l|l|l|l|}
\hline Generation & 1G & 2G & 3G & 4G & 5G \\
\hline Deployment & $1970 / 1984$ & $1980 / 1989$ & $1990 / 2002$ & 2000/2010 & 2017/2020 \\
\hline $\begin{array}{l}\text { Data } \\
\text { Bandwidth }\end{array}$ & $2 \mathrm{Kbps}$ & $14-64$ Kbps & 2 Kbps & $200 \mathrm{Kbps}$ & 1 Gbps \\
\hline Standards & AMPS & $\begin{array}{l}\text { TDMA, } \\
\text { CDMA, GPS, } \\
\text { GPRS }\end{array}$ & WCDMA & $\begin{array}{l}\text { Single } \\
\text { unified } \\
\text { standard }\end{array}$ & $\begin{array}{l}\text { Single } \\
\text { unified } \\
\text { standard }\end{array}$ \\
\hline Technology & $\begin{array}{l}\text { Analog } \\
\text { cellular } \\
\text { Cellular }\end{array}$ & $\begin{array}{l}\text { Bigital } \\
\text { with CDMA, } \\
\text { IP technology }\end{array}$ & $\begin{array}{l}\text { Unified IP } \\
\text { with LAN, } \\
\text { WAN } \\
\text { and WLAN }\end{array}$ & $\begin{array}{l}\text { Unified IP } \\
\text { with LAN, } \\
\text { WAN WLAN } \\
\text { and WLAN } \\
\text { and WWW }\end{array}$ \\
\hline Services & $\begin{array}{l}\text { Mobile } \\
\text { Technology } \\
\text { (voice) }\end{array}$ & $\begin{array}{l}\text { Digital voice, } \\
\text { SMS, Higher } \\
\text { capacity } \\
\text { packetized }\end{array}$ & $\begin{array}{l}\text { Integrated } \\
\text { high } \\
\text { quality audio } \\
\text { and video }\end{array}$ & $\begin{array}{l}\text { Dynamic } \\
\text { Information } \\
\text { Access, } \\
\text { Wearable } \\
\text { devices }\end{array}$ & $\begin{array}{l}\text { Dynamic } \\
\text { Information } \\
\text { Access, } \\
\text { Wearable } \\
\text { devices with } \\
\text { AI }\end{array}$ \\
\hline Multiplexing & FDMA & $\begin{array}{l}\text { CDMA, } \\
\text { TDMA }\end{array}$ & CDMA & CDMA & CDMA \\
\hline Switching & Circuit & $\begin{array}{l}\text { Circuit and } \\
\text { panel }\end{array}$ & Packet & All Packet & All Packet \\
\hline $\begin{array}{l}\text { Core } \\
\text { Network }\end{array}$ & PSTN & PSTN & $\begin{array}{l}\text { Packet } \\
\text { network }\end{array}$ & Internet & Internet \\
\hline Handoff & Horizontal & Horizontal & Horizontal & $\begin{array}{l}\text { Horizontal } \\
\text { and } \\
\text { Vertical }\end{array}$ & $\begin{array}{l}\text { Horizontal } \\
\text { and } \\
\text { Vertical }\end{array}$ \\
\hline
\end{tabular}

\subsection{Key Features of 5G Architecture}

- Lower Latency

- Huge Number of Connected Devices

- Decrease of Cost

- Improvement of Energy Efficiency

1.3 Applications of 5G Technology [8]

1) Real time wireless world

2) AI enabled wearable devices

3) Internet protocol version 6(IPv6),

4) One unified global standard.

5) Pervasive networks providing ubiquitous computing

The organization of this paper is as follows. In section II we have covered the state or art related to our research area, section III explains objectives of this research papers Final Section VII concludes and future of the paper.

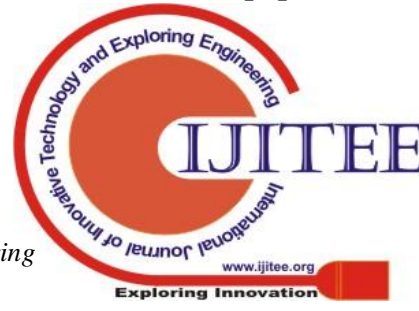




\section{LITERATURE REVIEW}

With the first-generation (1G) mobile communication network came the possibilities to make the first mobile phone calls. Then came the second-generation $(2 \mathrm{G})$ mobile network that enabled text messaging services like SMS and MMS. After that the third generation (3G) mobile network introduced light weight video streaming and enabled video calling to the public. The fourth generation (4G) mobile network then brought us high definition video streaming services and is, at the time of writing, the current standard. Qualcomm, 2014[20] The next step is the fifth generation $(5 \mathrm{G})$ mobile network which is expected to push the limits of mobile communication. Alongside the introduction of this new network technology are many new features to address the shortcomings of today's mobile communication solution.

These shortcomings have emerged as a result of our changing habits and increased demand on wireless mobile communication.

Until now the idea of the cellular infrastructure has been to build few, but powerful, cell towers to provide cellular coverage over large areas. This approach has worked well for the comparably limited connected mobile devices and their intended use. However, providing enough coverage and ensuring stable connections with low latencies are some of the many challenges facing the infrastructure today. Emergence of these challenges are due to several reasons:

- A dramatic increase of connected mobile devices.

- A demand for higher bandwidths to support more data transfer.

- A constant demand for higher connections speeds.

- A demand for reduced latency of connections.

- Metropolitan areas getting more densely populated.

As we know communication is an essential part of our society. Now a days there is era digital world with human-to-machine and machine-to-machine communication technologies. Over the time as the traffic on the network is increasing in seconds with congestion [1]. We need a approach that can help in the improvements of these problems, that can be achieved by using 5G networks [2], [3]. $5 \mathrm{G}$ networks provides the solutions with efficient and cost-effective launch for the society in different areas [4] [5]. As the security is also the measure concern for the society for securing their data and devices that support of secure digital markets [8] [9], [10].

There are many organizations are working in this area for designing an architecture for telecommunication networks. Some standards are given by 3GPP (3rd Generation Partnership Project) , which is working in telecommunication networks [11], that includes many requirements which includes various requirement and standardization documents for 5G[12].

Many researchers are working this area and many research papers has been published. In this section we have done literature survey in the area of $5 \mathrm{G}$ networks and security requirement for this new approach. Some papers have been included in our approach.

In Paper [13] different challenges included that shows the relationship between energy and spectral efficiency (EE vs.
$\mathrm{SE}$ ), trade of between these two, rethink signaling and control mechanisms for diverse traffic types, visibility of invisible base stations, they have also proposed the full duplex radio component for $5 \mathrm{G}$.

Boccardi et al. in [14], covers five disruptive viewpoints toward 5G approach, for enhancing the quality of the network, they have included traditional base station, how these can be more agile for handling the traffic over the network. How intelligent devices can help for enhancing the quality of network.

In paper [15] Network densification is explained, they explained how space and over frequency are the part of network and how user guarantee to enhanced user experience.

In paper [16] authors have done key observations like; 1) microcellular capacity is the problem due to its limit, 2) why update is required for mobile performance measurement. 3) Increasing in the various radio accessing and number of devices. In paper [17[ authors have given 5GNOW project's vision on $5 \mathrm{G}$ waveform designing

In paper [20] and [21] authors have included the problem of increasing data on mobiles and how data can be optimized on different handheld devices using IoT.

Paper [3] combines the user's point of for the old version and $5 \mathrm{G}$ networks. They have included How maximizing throughput; how high data rate is available for the users: How 5G Network can be secure?

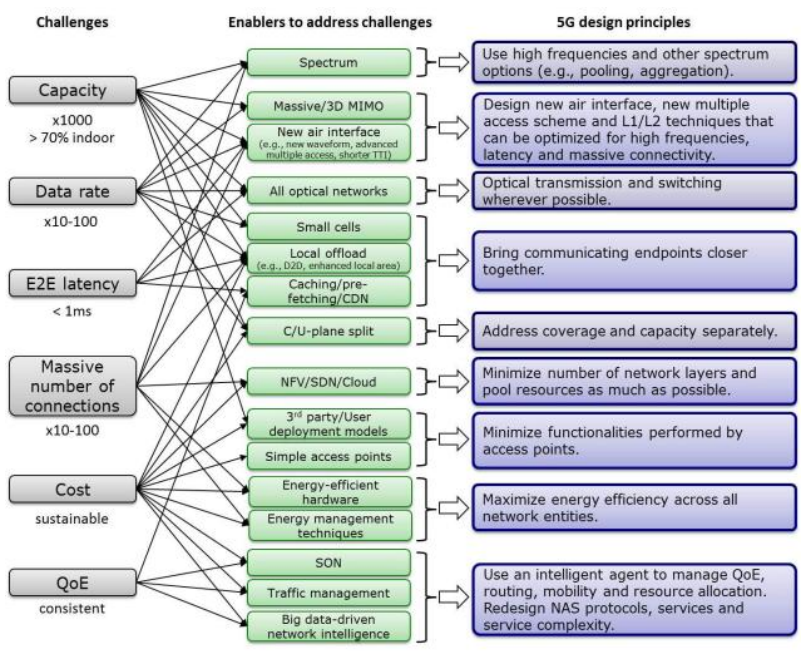

Figure $45 \mathrm{G}$ challenges, potential enablers and design principles

Paper [22,23] considered the current trends of network uses, they have combined all the $5 \mathrm{G}$ challenges, enablers and design principles, these challenges are briefly discussed in Figure 4. They have also included the security challenges on traditional approaches (Voice, Data, path security between nodes, SIM security etc.).

They have also included future security challenges for $5 \mathrm{G}$ networks, like when new business model will be created, IT-Driven Network Architecture, Heterogeneous access, Privacy Protection than what type security may be arises.

With 5G, this long-sought yet elusive goal finally promises to become a reality, ushering in new

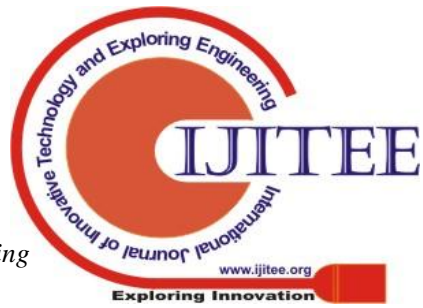


possibilities and opportunities, the extent of which seems limited only by our imagination [8].

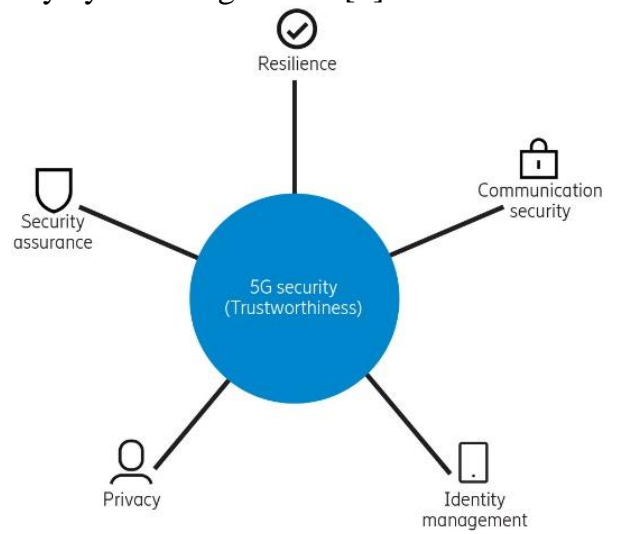

Figure 5 Trustworthiness properties of 5G system

\section{OBJECTIVES OF REASEARCH WORK}

Based on the literature reviewed we have studied in section 2; many works have been done by many researchers related our work. In this section, we have studied the $5 \mathrm{G}$ networks papers, we have concluded from the researcher work that, As the traffic on Internet is increasing day by day on $3 \mathrm{G}$ and $4 \mathrm{G}$ wireless technologies. So, there is requirement of 5th generation wireless communication networks expected to be in 2020 [1], [2]. As technical requirements over currently existing technologies (4G) [3] lists the following:

- Data volume per area for mobile should be 1000 times higher

- Data rate should be up to 100 times higher than normal users

- Connected devices should be up to 100 times higher existing

- Battery life should be 10 times longer for all devices

- Ende to end latency should be 5 times reducible

- End-to-end performance should be more

- There should be information of all connected devices

It is not a new phenomenon to use modern computers as aid, not only the planning and development but also the testing of new technologies.

The shift in mobile communication from a few powerful cell towers to many smaller cell towers requires a different approach when planning the network infrastructure. Increasingly more complex networks will be created with a multitude of nodes and connections between these nodes. Without the proper tools it will be hard, if not impossible, to predict the behavior of this kind of network, due to its complexity.

3.1 The main aim of the $5 \mathrm{G}$ networks is to provide the following benefits

- High Data Rate can be achieve using 5G networks

- Using this approach Energy consumption may be decreases

- Money may be save using this approach

- Congestion may be decrease on network

- 5G network also provide the good quality service (QoS)

- Download and Uploading time will be less

- It will support heterogeneous data downloading with high-Speed and clarity in Voice and Audio Calling
3.2 Main challenges in the $5 G$ network security perspectives [28-33]

- Multiple input, multiple output (MIMO). It should support the source (transmitter) and the destination (receiver) antennas than $4 \mathrm{G}$ base stations.

- Centimeter and millimeter wave. There should be more research to handle the spectrum's high frequencies, and including the spectrum's vulnerability to shadowing with extra speed on millimeter wave.

- Multi-Radio Access technologies. Devices may be connected different types of access points at the same time using LTE, Wi-Fi or with new approach.

- Small cells. In rural areas cells and antennas may be increased to increase number of option for the user to connect any time in these dense areas with more capability.

- Software Defined Networking (SDN). For improving the improving flexibility, facilitating centralized control, and ensuring easy network slicing, hardware and software with planes may be separate.

- Spectrum sharing. In 5G network spectrums may be shared to offer greater capacity with better of these utilization, and unique deployment scenarios.

- Battery life. This is the main issue in all the Generations, in $5 \mathrm{G}$ network battery life may be increase, which is the measure area of research with IoT.

- Ensuring end-to-end performance. This is the latest area of research for $5 \mathrm{G}$ network. Wireless connection should available for at least the last few feet or without "untethered," with unlimited capacity and infinite response" for the users.

- Contextual awareness. For end-to-end performance using this approach, 5G network will be able to understand what are the different types of devices are using, and which device is connected with network, with some information like, Location, Speed utilized, with some other parameters.

- Intelligent data mining on the fly with big data and heterogeneous data.

- Integration of latest approach like Machine learning, Artificial Learning, IoT, Deep Learning, Cloud Computing with distributed environment and intelligent capability to handle 5G network with new applications and advantage of an "always connected, always untethered, infinite capacity and response world.

\section{CONCLUSION}

Recently there are many researches is going on in network Generations and every year improving the network facilities for the users with betterment from 1st Generation to 4th Generation mobile communication technology. In 5G network there may be more enhancement and improvements in different areas which we have covered in Section 3.2.

Here we have studied many technologies related network communication and future of telecommunication standards Service with different challenges in this

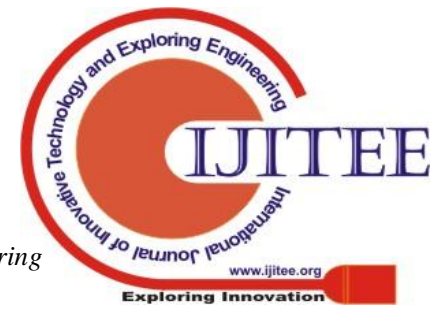


research area. On the basis of research, we have done in this paper.

Current fourth generation wireless networks offer many important innovations, but still leave significant room for improvement towards emerging fifth generation technology. Unfortunately, existing deployments do not generally provide technical solutions to benefit from context-related information, which is crucial to dramatically improve the levels of user experience. There should be intelligent networks with unlimited capacity that provide the End-to End performance capability for the user along with their locations and other information. Other thing, the 5G network should be able keep all the information related to connected devices that will helps to improve the quality of the network and adapting the network performance to best serve those parameters.

The novelty of our research may be relying on Ensuring end-to-end performance and context-aware services for heterogeneous networks which will be proposed to efficiently utilize dynamic context-related data in 5G network.

\section{REFERENCES:}

[1]. Ericsson, "Ericsson Mobility Report," 2017, available online at https://www:ericsson:com/assets/local/mobilityreport/ documents/2017/ericsson-mobility-reportjune-2017:pdf.

[2]. P. K. Agyapong, M. Iwamura, D. Staehle, W. Kiess, and A. Benjebbour, "Design considerations for a 5G network architecture," IEEE Communications Magazine, vol. 52, no. 11, pp. 65-75, 2014.

[3]. A. Osseiran, F. Boccardi, V. Braun, K. Kusume, P. Marsch, M. Maternia, O. Queseth, M. Schellmann, H. Schotten, H. Taoka, H. Tullberg, M. A.

[4]. Uusitalo, B. Timus, and M. Fallgren, "Scenarios for the $5 \mathrm{G}$ mobile and wireless communications: the vision of the METIS project," IEEE Communications Magazine, vol. 52, no. 5, pp. 26-35, 2014.

[5]. 5G Infrastructure Association, "5G and the factories of the future," 2015, available online

https://5g-ppp:eu/wp-content/uploads/2014/02/5G-PPP-White-Paper-on-F actoriesof-the-Future-Vertical-Sector:pdf.

[6]. — " $5 \mathrm{G}$ and e-health," 2015, available online at https: //5g-ppp:eu/wp-content/uploads/2016/02/5G-PPPWhite-Paper-on-eHealt h-Vertical-Sector:pdf.

[7]. 5G-PPP Software Networks Working Group, "Vision on software networks and 5G," 2017, available online at https://5g-ppp:eu/wp-content/uploads/2014/02/

5G-PPP_SoftNets_WG_whitepaper_v20:pdf.

[8]. ETSI, "GS NFV 002: Network functions virtualization (NFV); architectural framework," 2013, available online at http://www:etsi:org/deliver/etsi_gs/nfv/001_099/002/01:01:01_60/gs_nf v002v010101p:pdf.

[9]. ONF, “Software-Defined Networking (SDN) Definition." [Online]. Available: https://www:opennetworking:org/sdn-resources/sdn-definition

[10]. 5G Infrastructure Association, "5G vision," 2015, available online at https://5g-ppp:eu/wp-content/uploads/2015/02/5GVision-Brochure-v1:pd f.

[11]. "5G empowering vertical industries," 2016, available online at https://5g-ppp:eu/wp-content/uploads/2016/02/BROCHURE_5PPP_BA T2_PL:pdf.

[12]. 3GPP, "Release 15." [Online]. Available: http://www:3gpp:org/release-15

[13]. 3GPP, "TS 33.899: Study on the security aspects of the next generation system," 2017, available online at https:/portal:3gpp:org/desktopmodules/Specifications/SpecificationDetail s:aspx? specificationId $=3045$.

[14]. C.-L. I, C. Rowell, S. Han, Z. Xu, G. Li, and Z. Pan, "Toward green and soft: a 5G perspective,” IEEE Commun. Mag., vol. 52, pp. 66-73, Feb. 2014.
[15]. F. Boccardi, R. W. Heath Jr., A. Lozano, T. L. Marzetta, and P. Popovski, "Five disruptive technology directions for 5G," IEEE Commun. Mag., vol. 52, pp. 74-80, Feb. 2014.

[16]. N. Bhushan, J. Li, D. Malladi, R. Gilmore, D. Brenner, A. Damnjanovic, R. T. Sukhavasi, C. Patel, and S. Geirhofer, "Network densification: the dominant theme for wireless evolution into 5G," IEEE Commun. Mag., vol. 52, pp. 82-89, Feb. 2014.

[17]. B. Bangerter, S. Talwar, R. Arefi, and K. Stewart, "Networks and devices for the 5G era," IEEE Commun. Mag., vol. 52, pp. 90-96, Feb. 2014

[18]. G. Wunder, P. Jung, M. Kasparick, T. Wild, Y. Chen, S. ten Brink, I Gaspar, N. Michailow, A. Festag, L. Mendes, N. Cassiau, D. Kt'enas, M. Dryjanski, S. Pietrzyk, B. Eged, P. Vago, and F. Wiedmann, "5GNOW: non-orthogonal, asynchronous waveforms for future mobile applications," IEEE Commun. Mag., vol. 52, pp. 97-105, Feb. 2014

[19]. https://www.rfpage.com/how-5g-technology-works/

[20]. Qualcomm, "The 1000x Mobile Data Challenge," in White Paper, Nov 2013

[21]. NSN, "Signaling is Growing 50\% Faster than Data Traffic," in White Paper, 2012.

[22]. METIS, "Scenarios, Requirements and KPIs for 5G Mobile and Wireless System (Deliverable D1.1)," May 2013.

[23]. "Advanced 5G Network Infrastructure for the Future Internet - Public Private Partnership in Horizon 2020," 2013.

[24]. E. G. Larsson, F. Tufvesson, O. Edfors and T. L. Marzetta, "Massive MIMO for Next Generation Wireless Systems," May 2013.

[25]. Y. Kishiyama, A. Benjebbour, T. Nakamura and H. Ishii, "Future Steps of LTE-A: Evolution Toward Integration of Local Area and Wide Area Systems," IEEE Wireless Communications, vol. 20, no. 1, pp. 12-18, 2013

[26]. S. Gollakota, S. Perli and D. Katabi, "Interference Alignment and Cancellation," in ACM SIGCOMM Computer Communication Review, 2009.

[27]. odor, ahlman, ildh, ar vall, eider, i $1 \mathrm{~s}$ and Tur nyi, esign spects of Network Assisted Device-to-Device Communications," IEEE Communications Magazine, vol. 50, no. 3, pp. 170-177, 2012.

[28]. G. P. Fettweis, "A 5G Wireless Communications Vision," Microwave Journal, Dec 2012.

[29]. https://www.rcrwireless.com/20150721/test-and-measurement/top-10-a reas-for-5g-research-tag6

[30]. https://www.sdxcentral.com/5g/definitions/importance-5g-research/

[31]. Jussi Niutanen Intel Finland, Ixonos Tampere, Finland “ Improving Usability and Context Awareness over Fifth Generation (5G) Wireless Networks" PROCEEDING OF THE 15TH CONFERENCE OF FRUCT ASSOCIATION , pp. 209-211, 2014

[32]. Kashif Mahmood, Telenor Dirk Trossen, Interdigital "Context Awareness in Next Generation of Mobile Core Networks" 2016.

[33]. Tara Ali Yahiya ,1 Pinar Kirci ,2 and Andr'e-Luc Beylot3 "End-to-End Automation of 5G Networks" Hindawi Mobile Information Systems , Volume 2019, Article ID 6425419, 2019. 